\title{
Potencial tecnológico de harina de plátano verde con cáscara (Musa AAB) como sustituto de grasa para geles cárnicos
}

\section{Technological use of green banana flour with shell (Musa $A A B$ ) as a fat susbtitute for meat models}

\begin{abstract}
Araya-Quesada, Yorleny (1), Morales-Torres, Alejandra (1), Vargas-Aguilar, Pedro ${ }^{(1)}$, Wexler, Lea ${ }^{(1)}$.
(1) Universidad de Costa Rica, Facultad de Ciencias Agroalimentarias, Escuela de Tecnología de Alimentos,
\end{abstract} San Pedro de Montes de Oca, San José, Costa Rica.

Contacto: yorleny.araya@ucr.ac.cr

RECIBIDO: 27/05/2014 - APROBADO: 31/10/2014

\begin{abstract}
Resumen
Se evaluó harina de plátano verde con cáscara (Musa AAB Horn Plantain Cv. Harto) como sustituto de grasa para productos cárnicos. El producto se obtuvo mediante secado con aire a $70{ }^{\circ} \mathrm{C}$ y se realizó una molienda para obtener harina con dos tamaños de partícula (HF, HG). A esta se le determinó la composición proximal, capacidad de absorción de agua (WHC), solubilidad (S), hinchamiento (SW) y capacidad de absorción de grasa (FAC). Se elaboraron modelos de emulsiones cárnicas con 2, 4 y 6\% de harina a los cuales se les midió el pH, rendimiento de cocción, capacidad de retención de agua, perfil de textura y color. No se encontraron diferencias significativas para proteína, grasa, cenizas, almidón, $\mathrm{pH}$, color, WHC, S, SW y FAC entre las harinas. En los geles se determinaron diferencias significativas en el rendimiento de cocción, capacidad de retención de agua, dureza, gomosidad, masticabilidad y color; pero no en $\mathrm{pH}$, adhesividad, elasticidad y cohesión. Se determinó un descenso en los parámetros de color $\mathrm{L}^{\star}, \mathrm{b}^{\star}$ y $\mathrm{C}^{\star}$ al aumentar el grado de sustitución en las formulaciones. Se recomienda utilizar $4 \%$ de harina, lo cual representa un $20 \%$ de disminución de grasa.

Palabras clave: Geles cárnicos modelo, capacidad de retención de agua, capacidad de retención de grasa, textura.

Abstract

Green banana flour with shell was evaluated as fat substitute for meat products. Unripe plantains were dried in a hot air dryer $\left(70{ }^{\circ} \mathrm{C}\right.$ ) and milled by a hammer mill to obtain two flours with different mesh sizes (HF, HG). Proximal composition, water holding capacity (WHC), solubility (S), swelling (SW), and fat absorption capacity (FAC) were determined. $2 \%, 4 \%$ and $6 \%$ of HG and HF were added to a meat model emulsion as fat replacement. The effect of adding green banana flour was evaluated on cooking yield, water holding capacity, $\mathrm{pH}$, hardness, gumminess, chewiness, adhesiveness, elasticity, cohesiveness and color. There were not significant differences between both flours for protein, fat, ashes, WHC, S, SW, and FAC. No significant differences were found for adhesiveness, elasticity, and cohesiveness. A drop in $\mathrm{L}^{\star}, \mathrm{b}^{\star}$ and $\mathrm{C}^{\star}$ parameters regarding the control gel was determined with the increase of fat substitution. We recommend a substitution percentage equal or lower than $4 \%$, which represents a $20 \%$ of fat reduction.

Keywords: Meat product model, water holding capacity, fat absorption capacity, texture.
\end{abstract}

\section{Introducción}

El plátano pertenece al género Musa; a la familia Musaceae y al orden de las zingiberáceas. Los biotipos cultivados se basan en los genomas AA para el grupo acuminata y BB para el grupo balbisiana, lo cual se reúne en los triploides $\mathrm{AAA}, \mathrm{AAB}$ y $\mathrm{ABB}$. Los plátanos $\mathrm{AAB}$ pertenecen al grupo paradisíaca, entre los cuales se encuentran el Dominico (French Plantain), el Curraré (Horn Plantain) y el Liberal (Murillo y Pacheco, 1994; Smith y Velásquez, 2004).

Los plátanos son uno de los principales alimentos básicos en África, América Latina, el Caribe y la India
(FAO, 2011). La producción mundial del plátano tiende a aumentar y es un fruto disponible todo el año en las regiones tropicales y subtropicales (Sarawong, et al., 2014). Shaibu et al. (2012) señalan que los bananos y plátanos representan el segundo fruto de mayor cosecha a nivel mundial con 129.906.098 toneladas métricas en 2010, y es el cuarto producto alimenticio en importancia a nivel mundial. En Costa Rica, según la Secretaría Ejecutiva de Planificación Sectorial Agropecuaria, SEPSA (2011), en los últimos años se ha dado un aumento en el área de producción del plátano, hasta alcanzar en 2010 un área sembrada de 10.000 hectáreas. 
Los frutos verdes y maduros que no se comercializan en fresco pueden ser aprovechados para alimentación humana en la elaboración de chips, cremas, panes, tortas, helados, batidos, mermeladas, purés, productos lácteos como los yogures, bebidas sazonadas y alcohólicas, alimentos infantiles, salsas, producción de harina como fuente de fibra dietética, en la extracción de almidones nativos y la obtención de almidones modificados, y alimentos concentrados para la alimentación animal (González y Pacheco-Delahaye, 2006; González, et al., 2009; Mazzeo, et al., 2010). Además, estas harinas y almidones se utilizan para la elaboración de pastas alimenticias y productos de panificación (Mazzeo, et al., 2010).

El plátano presenta muchos beneficios para la salud debido a su composición de fibra dietética total (FDT), almidón total (AT), almidón disponible (AD) y almidón resistente (AR) y compuestos fenólicos cuando no ha madurado (González y Pacheco-Delahaye, 2006; Islas, et al., 2007; Sarawong, et al., 2014). Además, es rico en vitamina B6, vitamina C, calcio, hierro, magnesio, potasio y fósforo (Hernández, et al., 2009; Molina, 2001). Restrepo (2002) sugiere el uso del plátano como una sustancia de relleno en alimentos, debido a su capacidad retenedora de humedad, lo cual extiende el volumen de las formulaciones, abaratando costos de producción e incorporando propiedades funcionales. A su vez, González y Pacheco-Delahaye (2006) utilizan las propiedades de gelificación de la harina de plátano para elaborar geles de piña a partir de jugos clarificados.

Para determinar la posibilidad de uso de la harina de plátano en productos cárnicos, el uso de modelos resulta conveniente para definir el impacto de condiciones de proceso. Los modelos de emulsiones cárnicas son sistemas que se componen de los principales componentes del producto cárnico, en el que se sustituye una proporción de algún componente por algún ingrediente funcional, generalmente reemplazos de proteínas o grasas (Codex Alimentarius, 1989; Tokusoglu y Kemal, 2003).

El uso de geles modelo permite realizar investigaciones de una forma más económica, ya que se utilizan los componentes principales de la formulación a menor escala. Esta metodología ha sido aplicada por una gran variedad de investigadores para evaluar propiedades tecnológicas de sustancias como la $\kappa$-carragenina, la albúmina de huevo y la transglutaminasa (Pietrasik, 2003), y el efecto como ingrediente funcional de materias primas como la fibra de salvado de arroz (Choi, et al., 2011), la fibra de coliflor (Femenia, et al., 1997), la fibra de naranja (Bortoluzzi, et al., 2005) y las algas comestibles (López-López, et al., 2009).

Debido a la relación entre el consumo de grasa y el desarrollo de enfermedades cardiovasculares ha aumentado la necesidad de desarrollar productos con menos contenido de grasa. Para evitar cambios en las características sensoriales y químicas, y en consecuencia el rechazo del producto por parte del consumidor, se ha intentado sustituir la grasa por ingredientes no cárnicos o ligantes (Pinero, et al., 2008). Dado que el plátano y su cáscara son fuentes ricas en polisacáridos, el objetivo de este proyecto es evaluar el potencial tecnológico de dos harinas de plátano verde con cáscara, variedad curraré (Musa AAB Horn Plantain $C v$. Harto) con diferentes tamaños de partícula, con el fin de determinar la factibilidad de utilizarla como sustituto de grasa en productos cárnicos mediante geles modelo con adición de $2 \%, 4 \%$ y $6 \%$ de las harinas.

\section{Materiales y Métodos}

\section{Materia prima}

Se utilizó plátano verde de 7 semanas de desarrollo fisiológico, proveniente del cantón de Matina en la provincia de Limón, Costa Rica.

\section{Proceso de elaboración de la harina}

Los plátanos se lavaron y se desinfectaron por inmersión en una disolución de ácido peracético a $80 \mathrm{mg} / \mathrm{kg}$ durante 5 minutos. Luego, se les eliminaron las puntas y seguidamente se trocearon en cubos con un tamaño de $1 \mathrm{~cm}$ de arista empleando una cortadora Hobart. Los trozos de plátano se secaron con aire caliente (The National Drying Machine Co., TY2-48397) a $70{ }^{\circ} \mathrm{C}$ y una velocidad de aire de $5,4 \mathrm{~m} / \mathrm{s}$ hasta alcanzar una humedad de $2-3 \%(\mathrm{~m} / \mathrm{m})$. El plátano seco se procesó en un molino de martillos (Tainea S.A., TEW 21) con dos mallas de 0,33 y 0,63 pulgadas para obtener distintos tamaños de partícula, harina fina y gruesa, respectivamente. Producto de la molienda realizada el $67,48 \%$ de la harina fina HF presenta un tamaño de partícula inferior a $0,0555 \mathrm{~mm}$, y en el caso de la harina gruesa $\mathrm{HG}$ el $68,87 \%$ presenta un diámetro de partícula superior a $0,0530 \mathrm{~mm}$ e inferior a $0,2105 \mathrm{~mm}$. Ambas harinas se empacaron en bolsas de polietileno de alta densidad y se almacenaron a temperatura ambiente. Se hicieron tres repeticiones del proceso de la harina.

\section{Caracterización de la harina de plátano}

\section{Composición proximal}

La humedad se midió en una muestra de 5 g que se secó a $70^{\circ} \mathrm{C}$ en estufa de vacío, adaptando el método 925.09 AOAC (1990c). El contenido de cenizas se determinó mediante la calcinación según el método 923.03 AOAC (1990b). La grasa se determinó con extractor de Soxhlet, siguiendo el método 920.85 de la AOAC (1990a). La cuantificación de proteína se realizó en forma indirecta por medio del contenido de nitrógeno total utilizando el método de Kjeldahl AOAC 920.152 (AOAC, 2005). El almidón se determinó enzimáticamente hidrolizando con amiloglucosidasa y se cuantificó espectrofotométricamente la concentración de glucosa (Mestres, et al., 1993). Se realizaron las mediciones por triplicado de cada una de las tres repeticiones.

\section{Propiedades tecnológicas de la harina}

\section{Capacidad de retención de agua (WHC)}

Se modificó la metodología descrita por Femenia et al. (1997); 2,5 g de harina se suspendieron en $50 \mathrm{~mL}$ de disolución buffer de fosfatos de $1 \mathrm{~mol} / \mathrm{L}$ a pH 6,3 y se dejó en reposo por 24 horas. Luego se centrifugaron 4,5 minutos a $6000 \mathrm{rpm}$; los residuos sólidos recuperados por filtración se colocaron en cápsulas de porcelana a masa constante y se secaron en estufa de vacío a $70{ }^{\circ} \mathrm{C}$ hasta obtener masa constante. La WHC se calculó con las expresiones (Femenia, et al., 1997): 
$W H C=\frac{\left(m_{\text {cápsula }+ \text { muestra }}-m_{\text {cápsula }+ \text { residuo }}\right)}{\left(m_{\text {cápsula }+ \text { residuo }}-k\right)}$

Donde, a ( $\left.m_{\text {cápsula }+ \text { muestra }}-m_{\text {cápsula }+ \text { residuo }}\right)$, $\mathrm{a}=2,8 \times 10^{-2} \mathrm{~g} \mathrm{PO}^{-4} / \mathrm{mL}$

\section{Solubilidad (S)}

La solubilidad se midió por triplicado en conjunto con la capacidad de retención de agua, y se expresó como porcentaje de pérdida en el peso de la muestra original en seco (corregida por la presencia del buffer de fosfato) después de la recuperación de material insoluble utilizado para determinar la WHC (Femenia, et al., 1997). Se calculó de la siguiente forma:

Solubilidad $=m_{\text {muestra }}-\frac{\left(m_{\text {residuo }}-k\right)}{m_{\text {muestra }}}$

Donde, $k=$ a $\left(m_{\text {cápsula }+ \text { muestra }}-m_{\text {cápsula }+ \text { residuo }}\right)$, $\mathrm{a}=2,8 \times 10^{-2} \mathrm{~g} \mathrm{PO}^{-4} / \mathrm{mL}$

\section{Hinchamiento (SW)}

Se hidrataron, por triplicado, $0,5 \mathrm{~g}$ de muestra con $10 \mathrm{~mL}$ de buffer de fosfatos en una probeta y se dejó reposar durante 24 h. Se determinó el volumen de harina que se hidrató con el buffer y el resultado se expresa como $\mathrm{mL}$ de residuo/g muestra seca (Femenia, et al., 1997).

\section{Capacidad de absorción de grasa (FAC)}

Se midió gravimétricamente utilizando el método modificado descrito por Femenia et al. (1997), para lo cual se mezcló por triplicado muestras de $5 \mathrm{~g}$ de la harina con $30 \mathrm{~mL}$ de aceite de girasol y se dejó en reposo durante 24 horas a temperatura ambiente. Luego se centrifugó 3,5 minutos a $6000 \mathrm{rpm}$, se decantó el líquido sobrenadante y la FAC se expresó como g aceite/g muestra seca.

\section{Propiedades de los geles cárnicos}

Proceso de elaboración de los geles modelo

La formulación del gel modelo se obtuvo de modificar lo descrito por Bortoluzz et al., 2005 y Chang y Carpenter, 1997 (Tabla 1). Se elaboraron geles modelo conteniendo 0 (control), 2,4 y $6 \%(\mathrm{~m} / \mathrm{m})$ de las harinas de plátano, reduciéndose el contenido de grasa (aceite de soya) y aumentando el porcentaje de agua a medida que se incrementó el porcentaje de harina.

Los geles modelo se procesaron según la metodología modificada de Choi et al. (2011), para lo cual la pechuga de pollo sin piel, desgrasada y deshuesada se picó en un procesador de alimentos (Hobart) durante 1 minuto a $4{ }^{\circ} \mathrm{C}$, se mezcló en un procesador de alimentos (Black y Decker, HC300 Handy Chopper Pluss TM) con el resto de los ingredientes durante 1 minuto a $4{ }^{\circ} \mathrm{C}$ y se adicionó harina de plátano en caso de que el gel tuviera un grado de sustitución. Posteriormente, la pasta obtenida se transfirió a tubos de centrífuga de $50 \mathrm{~mL}$, se taparon y se centrifugaron a $2500 \mathrm{rpm}$ durante 1 minuto para eliminar las burbujas de aire.

La mezcla se llevó a $20^{\circ} \mathrm{C}$ durante 10 minutos en un baño de agua (Digisystem Laboratory Instruments Inc., 1009045) y luego se calentó a $90^{\circ} \mathrm{C}$ durante 20 minutos, aumentando el calor a una velocidad de $2{ }^{\circ} \mathrm{C} / \mathrm{min}$. Los tubos de centrífuga se sumergieron en un baño de agua con hielo durante 20 minutos y se refrigeraron a $4{ }^{\circ} \mathrm{C}$ durante 24 horas.

\section{Evaluación de los geles}

$\mathrm{pH}$

Se midió por triplicado siguiendo la metodología sugerida por Choi et al. (2011) con un pHmetro (Metrohm, 827 pH lab).

Rendimiento de cocción

El rendimiento se determinó como la diferencia porcentual entre las masas de los geles crudos y cocidos. Luego de la

\begin{tabular}{|c|c|c|c|c|c|c|c|}
\hline \multirow{3}{*}{ Ingrediente } & \multicolumn{7}{|c|}{ Porcentaje (\% m/m) } \\
\hline & \multirow{2}{*}{ Control } & \multicolumn{3}{|c|}{ Harina gruesa } & \multicolumn{3}{|c|}{ Harina fina } \\
\hline & & Gel 1 & Gel 2 & Gel 3 & Gel 4 & Gel 5 & Gel 6 \\
\hline Carne de pollo molida & 50,0 & 50,0 & 50,0 & 50,0 & 50,0 & 50,0 & 50,0 \\
\hline Aceite de soya & 25,0 & 22,5 & 20,0 & 17,4 & 22,5 & 20,0 & 17,4 \\
\hline Agua destilada & 22,7 & 23,2 & 23,7 & 24,3 & 23,2 & 23,7 & 24,3 \\
\hline Cloruro de sodio & 2,0 & 2,0 & 2,0 & 2,0 & 2,0 & 2,0 & 2,0 \\
\hline Tripolifosfato de sodio & 0,3 & 0,3 & 0,3 & 0,3 & 0,3 & 0,3 & 0,3 \\
\hline Harina de plátano & 0,0 & 2,0 & 4,0 & 6,0 & 2,0 & 4,0 & 6,0 \\
\hline Reducción aceite de soya & 0,0 & 2,5 & 5,0 & 7,6 & 2,5 & 5,0 & 7,6 \\
\hline Aumento agua destilada & 0,0 & 0,5 & 1,0 & 1,6 & 0,5 & 1,0 & 1,6 \\
\hline Reducción de grasa & 0,0 & 10,1 & 20,2 & 30,3 & 10,1 & 20,2 & 30,3 \\
\hline
\end{tabular}

Tabla 1. Formulación de los geles modelo para evaluar sus propiedades tecnológicas. 
cocción a $90^{\circ} \mathrm{C}$ durante 20 minutos se procedió a decantar el líquido sobrenadante, se enfrió y se midió la masa.

\section{Capacidad de adsorción de agua (WHC)}

Se siguió la metodología de Choi et al. (2011) modificada. $\mathrm{Al}$ preparar los geles modelo, luego de que se mantuvo la temperatura a $90^{\circ} \mathrm{C}$ durante 20 minutos en el baño de agua (Digisystem Laboratory Instruments Inc., 1009045), se decantó el líquido sobrenadante y se midió su masa. Los geles se almacenaron a $4{ }^{\circ} \mathrm{C}$ durante 24 horas y posteriormente se centrifugaron (Labnet, HERMLE Z300) a 6000 rpm durante 1 minuto y se midió la masa de los geles centrifugados y cocidos. Las mediciones se realizaron por triplicado. WHC se calculó mediante la fórmula:

$W H C=\left(1-\frac{m_{\text {gel centrifugado }}}{m_{\text {gel cocido }}}\right) * 100$

\section{Análisis del perfil de textura (TPA)}

La textura de los geles modelos se midió con un texturómetro (TA.TX Plus, Stable Micro Systems) con celda de carga de 50,0 kg, utilizando muestras cilíndricas de 2,0 cm de altura que se comprimen dos veces al $50 \%$ de su altura original con $1,0 \mathrm{~mm} / \mathrm{s}$ de velocidad de cabezal, $1,0 \mathrm{~mm} / \mathrm{s}$ de velocidad de pre-prueba, $1,0 \mathrm{~mm} / \mathrm{s}$ de velocidad de post-prueba, $2 \mathrm{~kg}$ de carga máxima, 10,000 $\mathrm{mm}$ de distancia; 5,00 s de tiempo y 25,0 g de fuerza. Se obtuvieron los parámetros de: dureza (pico de fuerza en la primera compresión, $\mathrm{N}$ ), elasticidad (distancia entre la primera compresión y la segunda), cohesión (razón entre el área del segundo pico de fuerza y el primero), adhesividad (área del tercer pico de fuerza), gomosidad (dureza * cohesión) y masticabilidad (dureza * cohesión ${ }^{*}$ elasticidad) (Choi, et al., 2011). Para la determinación se realizaron seis mediciones de cada una de las tres repeticiones.

\section{Color}

Se determinó usando un colorímetro (Hunter Lab, Color Flex), calibrado con un plato negro, uno blanco y uno verde $\left(L^{*}=53,11 ; a^{*}=-26,13 y b^{*}=12,28\right)$ a una diferencia de \pm 0,30 . Se midieron los parámetros $L^{*}, a^{*} y b^{*}$ por triplicado. La intensidad de color se calculó como $C^{\star}=(\mathrm{a} 2+\mathrm{b} 2) 1 / 2$ y el ángulo de matiz se calculó $\mathrm{h}^{\circ}=\operatorname{artctan}\left(\mathrm{b}^{\star} / \mathrm{a}^{\star}\right)(\mathrm{Choi}$, et al. 2011).

\section{Análisis de datos}

Para la caracterización de las harinas los resultados se reportaron como el promedio entre los valores obtenidos en las tres repeticiones con su respectiva desviación estándar y se analizaron estadísticamente con una $t$-student. Para la evaluación de los geles se utilizó un diseño irrestricto aleatorio con siete tratamientos y tres repeticiones. Las variables respuesta se analizaron estadísticamente mediante un ANDEVA y en caso de detectar diferencias significativas al 95\% de confianza se aplicó una prueba de comparación de medias Tukey. En los parámetros en los que no se detectaron diferencias significativas se calculó la potencia de la prueba para el análisis estadístico.

\section{Resultados}

Se determinaron diferencias significativas entre ambas harinas para los contenidos de humedad, carbohidratos y almidón, mientras que no se hallaron diferencias significativas para los contenidos de cenizas, grasa y proteína (Tabla 2).

\begin{tabular}{|l|c|c|c|}
\hline \multirow{2}{*}{ Variable } & \multicolumn{2}{|c|}{$\begin{array}{c}\text { Contenido } \\
(\% \mathrm{~m} / \mathrm{m} \text { en base seca })\end{array}$} & \multirow{2}{*}{ Probabilidad } \\
\cline { 2 - 3 } & $\begin{array}{c}\text { Harina } \\
\text { gruesa }\end{array}$ & $\begin{array}{c}\text { Harina } \\
\text { fina }\end{array}$ & \\
\hline Humedad & $2,85 \pm 0,07 \mathrm{a}$ & $2,29 \pm 0,07 \mathrm{~b}$ & 0,0287 \\
\hline Cenizas & $3,41 \pm 0,14$ & $3,23 \pm 0,14$ & 0,4561 \\
Grasa & $1,13 \pm 0,16$ & $0,610 \pm 0,16$ & 0,1502 \\
\hline Proteína & $3,78 \pm 0,07$ & $3,48 \pm 0,07$ & 0,0881 \\
Carbohidratos & $91,7 \pm 0,03^{\mathrm{a}}$ & $92,7 \pm 0,03^{\mathrm{b}}$ & 0,0021 \\
\hline Almidón total & $68,6 \pm 0,53$ & $69,6 \pm 0,53$ & 0,0245 \\
\hline
\end{tabular}

Tabla 2. Composición proximal de harinas de plátano (Musa $A A B)$ verde con cáscara de diferente tamaño de partícula. ${ }^{\star}$ Letras diferentes entre la fila indican diferencias significativas con un $95 \%$ de confianza.

No se determinaron diferencias significativas en ninguna de las cuatro propiedades tecnológicas evaluadas (Tabla 3).

\begin{tabular}{|l|c|c|c|}
\hline \multirow{2}{*}{ Variable } & \multicolumn{2}{|c|}{ Valor } & \multirow{2}{*}{ Probabilidad } \\
\cline { 2 - 3 } & $\begin{array}{c}\text { Harina } \\
\text { gruesa }\end{array}$ & $\begin{array}{c}\text { Harina } \\
\text { fina }\end{array}$ & \\
\hline WHC $(\mathrm{g} / \mathrm{g})$ & $1,58 \pm 0,11$ & $1,54 \pm 0,05$ & 0,1675 \\
$\mathrm{~S}(\mathrm{~g} / \mathrm{g})$ & $1,59 \pm 0,02$ & $1,58 \pm 0,02$ & 0,8302 \\
$\mathrm{SW}(\mathrm{mL} / \mathrm{g})$ & $3,77 \pm 0,17$ & $3,91 \pm 0,17$ & 0,6222 \\
FAC $(\mathrm{g} / \mathrm{g})$ & $0,795 \pm 0,02$ & $0,788 \pm 0,02$ & 0,8617 \\
\hline
\end{tabular}

Tabla 3. Propiedades tecnológicas evaluadas para las harinas de plátano con diferente tamaño de partícula.

Los valores de $\mathrm{pH}$ de la mezcla cárnica se encontraron en un rango entre 6,07-6,10 y no presentaron diferencias significativas $(p=0,5621)$, es decir, ni el grado de sustitución ni el tipo de harina que se utilizó tuvo influencia sobre el $\mathrm{pH}$, por lo que se asegura que los geles no sufrirían cambio de textura producto de variaciones del $\mathrm{pH}$.

En el Gráfico 1 se presentan los resultados del rendimiento de cocción y la capacidad de adsorción de agua de los geles cárnicos elaborados.

Mediante el Análisis de Perfil de Textura (TPA) (Gráfico 2) se determinaron diferencias significativas entre los tratamientos para las variables de dureza $(\mathrm{p}=0,0128)$, gomosidad $(\mathrm{p}=$ $0,0059)$ y masticabilidad $(p=0,0059)$. La elasticidad, cohesividad $(\mathrm{p}=0,6566)$ y adhesividad $(\mathrm{p}=0,7344)$ no mostraron diferencias significativas entre los geles formulados. 


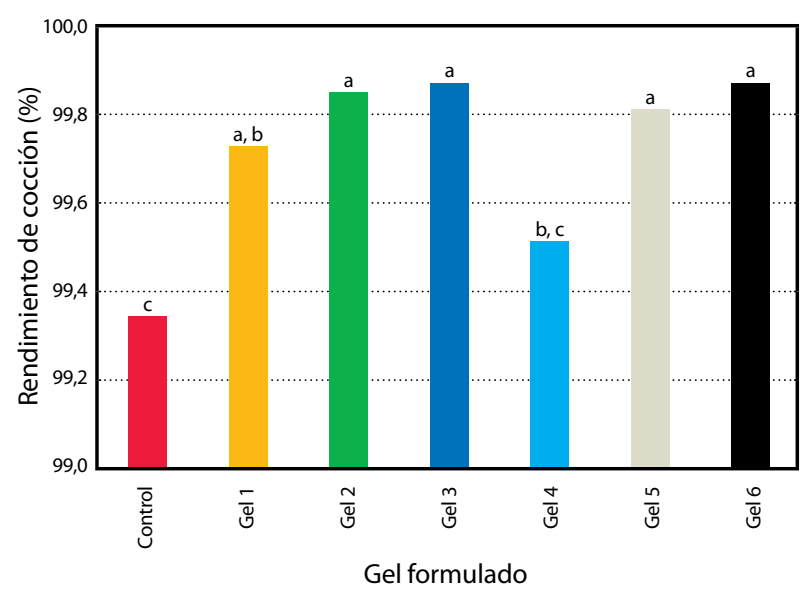

b.

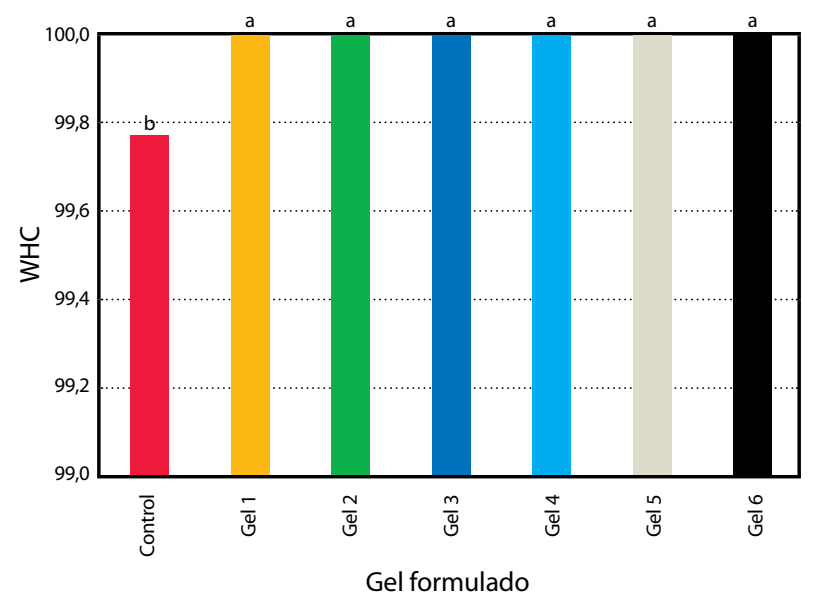

Gráfico 1. Efecto de la adición de harina de plátano con cáscara con diferentes tamaños de partícula y grados de sustitución sobre el rendimiento de cocción (a) y la capacidad de adsorción de agua (b) en geles cárnicos.

a.

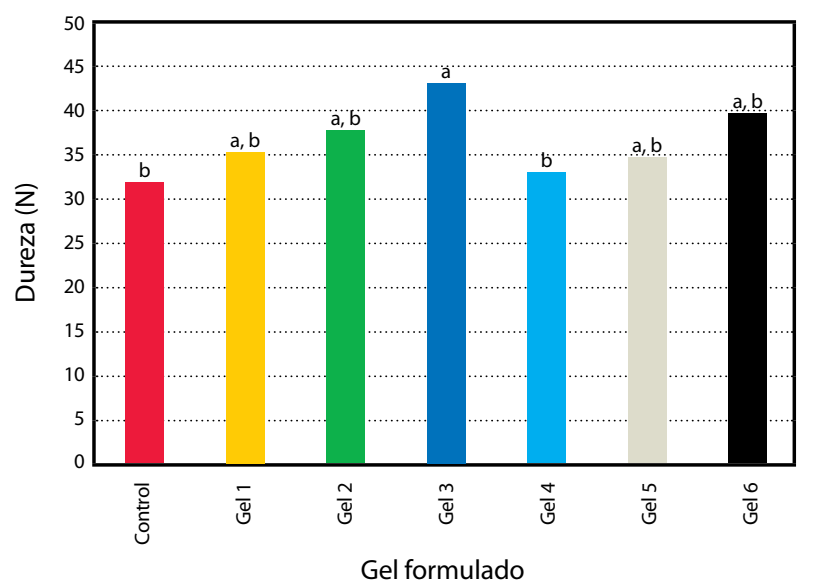

c.

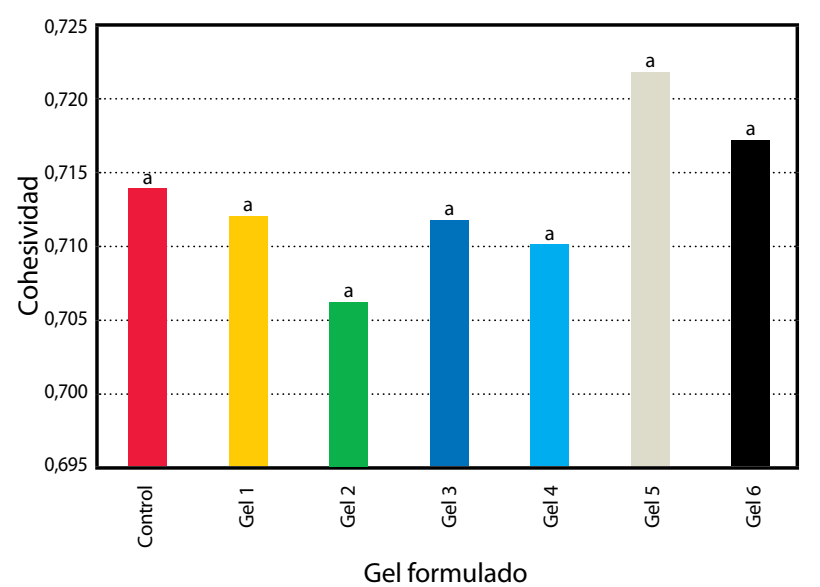

b.

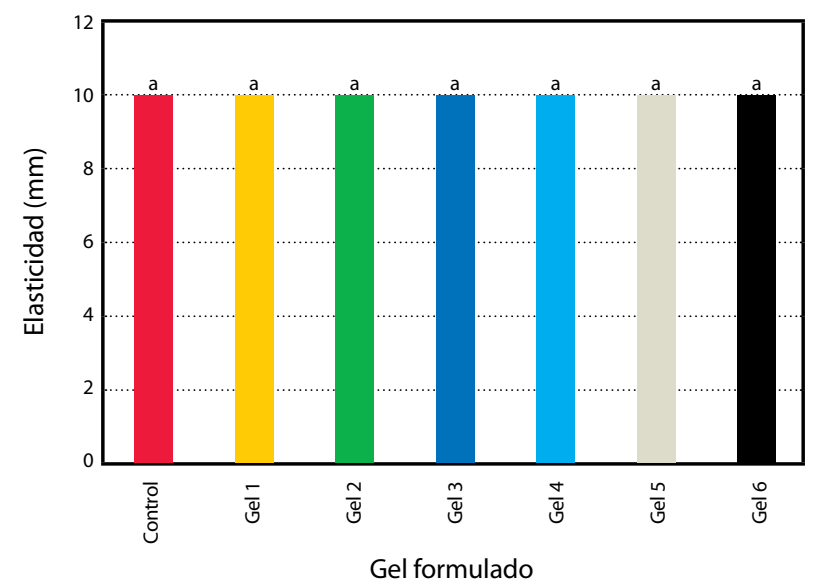

d.

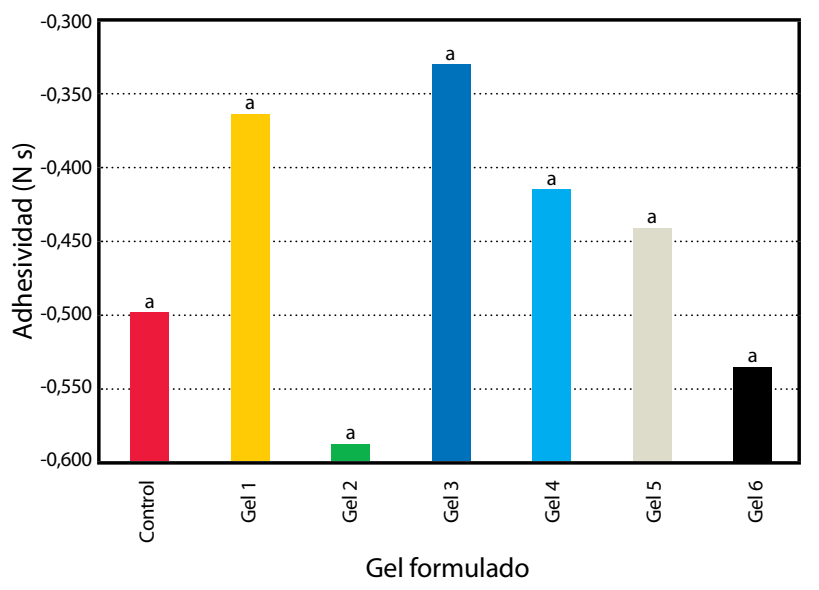




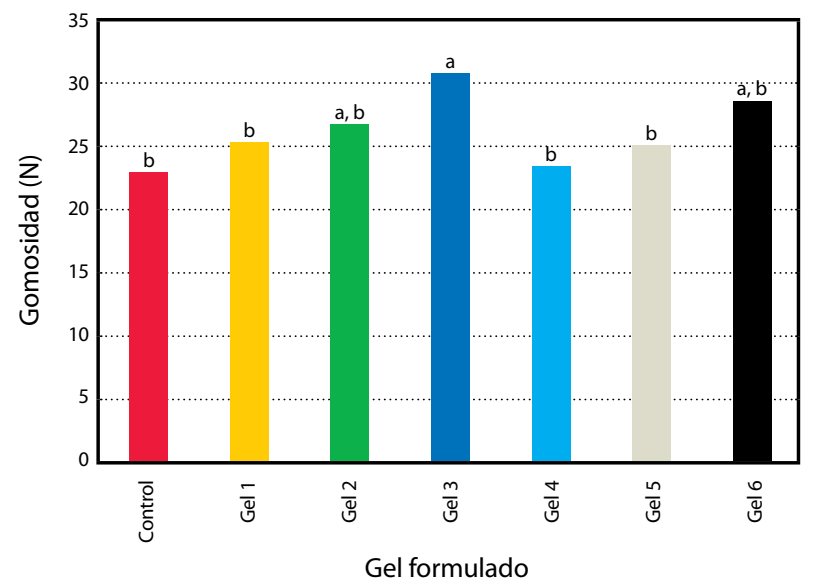

f.

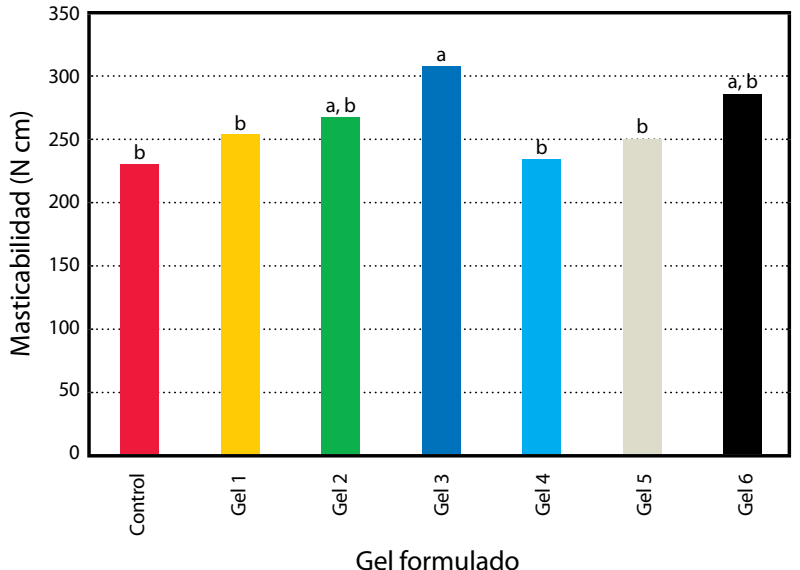

Gráfico 2. Efecto de la adición de harina de plátano con cáscara con diferentes tamaños de partícula y grados de sustitución sobre la dureza (a), elasticidad (b), cohesividad (c), adhesividad (d), gomosidad (e) y masticabilidad (f) en geles cárnicos.

Se obtuvieron diferencias significativas para los parámetros de luminosidad visual $\left(\mathrm{L}^{*}\right)(\mathrm{p}<0,0001)$, enrojecimiento $\left(\mathrm{a}^{*}\right)(\mathrm{p}=0,0001)$, amarillo $\left(\mathrm{b}^{*}\right)(\mathrm{p}<0,0001)$, croma $\left(\mathrm{C}^{*}\right)(\mathrm{p}<0,0001)$ y ángulo de matiz $\left(\mathrm{h}^{\circ}\right)(\mathrm{p}=0,0001)$ para los geles formulados (Gráfico 3).

a.

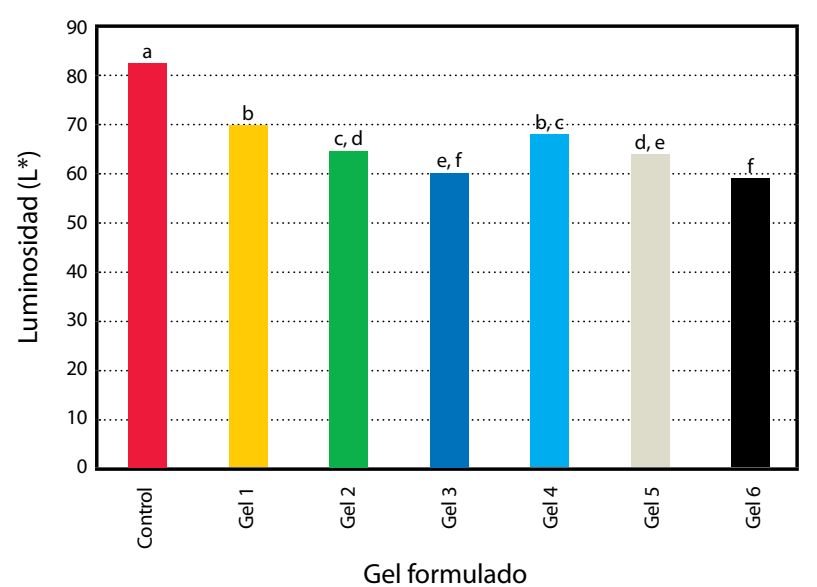

c.

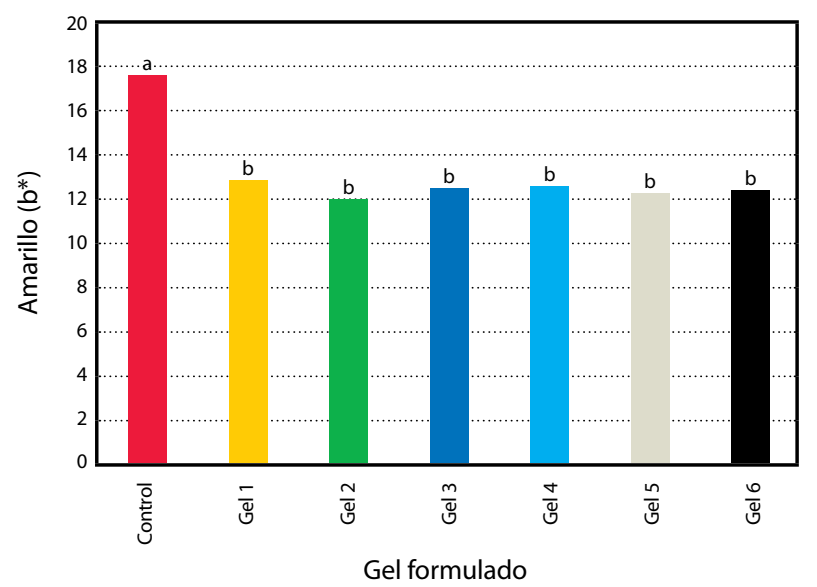

b.



d.

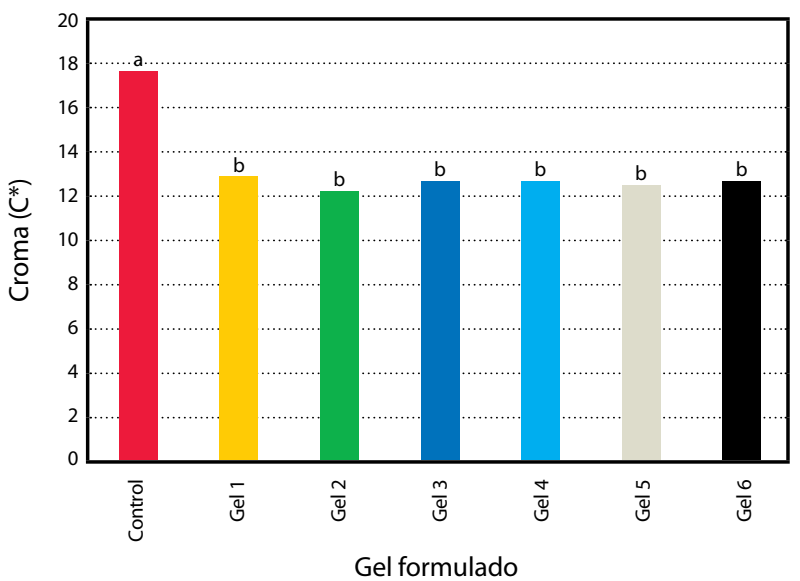




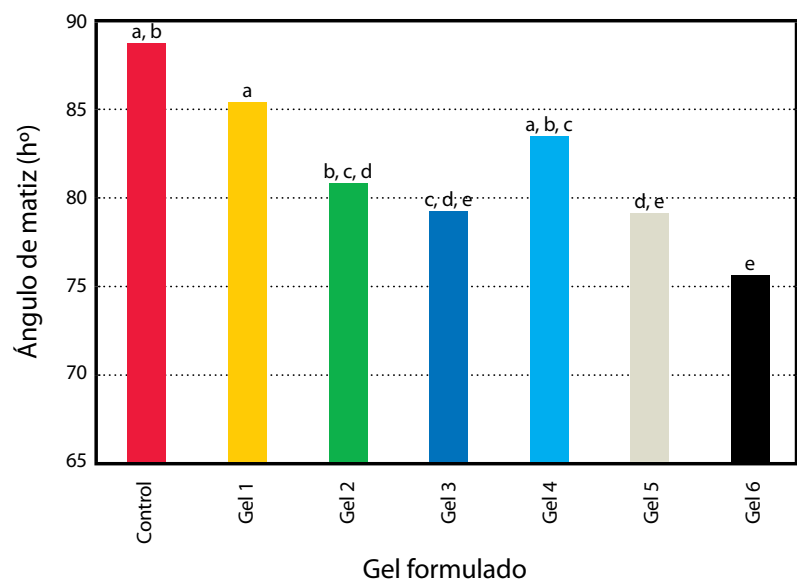

Gráfico 3. Efecto de la adición de harina de plátano con cáscara con diferentes tamaños de partícula y grados de sustitución sobre la luminosidad visual (a), el enrojecimiento (b), el amarillo (c), el croma (d) y el ángulo de matiz (e) en geles cárnicos.

\section{Discusión}

\section{Caracterización de la harina de plátano verde con cáscara}

Las diferencias del contenido de humedad (Tabla 2) pueden deberse a que durante el proceso de secado por aire caliente no se controló regularmente el descenso de humedad, sino que se fijó un tiempo de secado.

Respecto al contenido de carbohidratos, se determinaron diferencias significativas entre los dos tipos de harina, siendo mayor para la harina fina. Durante el proceso de molienda de la harina fina se observó una gran cantidad de cáscara retenida en comparación con la harina gruesa, lo que pudo ocasionar una variación en la proporción. Las harinas obtenidas tienen altos porcentajes de almidón; González y Pacheco-Delahaye (2006) mencionan que el almidón proveniente del plátano proporciona pastas cortas que en el enfriamiento producen geles de gran fuerza. Tapia (2005) indica que el plátano contiene almidón resistente tipo 2 (AR2), el cual presenta una estructura parcialmente hidratada y gelatinizada tan empaquetada que limita la accesibilidad de las amilasas. Además, cuando estas estructuras se calientan y rehidratan, la amilosa forma una estructura de almidón resistente complejo y estable (almidón resistente tipo 3, AR3), el cual es altamente resistente a las enzimas amilolíticas (Tapia, 2005) que lo convierten en un ingrediente funcional (Soto, 2010).

\section{Evaluación de las propiedades tecnológicas de la harina}

En las condiciones del estudio el tamaño de partícula no influye en la capacidad de retención de agua, solubilidad, hinchamiento, ni en la capacidad de adsorción de grasa de las harinas (Tabla 3).

Sangnark y Noomhorm (2003) realizaron un estudio del efecto del tamaño de partícula sobre las propiedades funcionales de la fibra dietética y determinaron que una disminución en el tamaño de partícula de la fibra se asoció con un aumento en la densidad y una reducción de la WHC y FAC. Sin embargo, Raghavendra et al. (2006) indican que una reducción en el tamaño de partícula de 1127 a $550 \mu \mathrm{m}$ tiene un efecto significativo en la estructura física de las fibras de coco y que esto se relaciona con un aumento de las propiedades de hidratación - tales como la capacidad de retención de agua, capacidad de adsorción de agua e hinchamiento-, de forma tal que las propiedades de hidratación tienden a disminuir conforme aumenta el tamaño de partícula.

Sangnark y Noomhorm (2003), en su estudio con Laminaria digitata (kombu bretón), encontraron que tamaños de partícula menores se asociaron con una adsorción de agua y grasa mayor. Asimismo, parámetros experimentales como la agitación podrían alterar la estructura física de las fibras y dar lugar a grandes cambios en la WHC y FAC.

Estos resultados indican que los tamaños de partícula utilizados en esta investigación no fueron lo suficientemente diferentes para detectar una diferencia, si es que existe una. Por otra parte, si se considera que la composición química en general no mostró diferencias, se podría decir que esta no influyó sobre las propiedades tecnológicas ni tampoco sobre la superficie de contacto, o bien que un contenido mayor de cáscara en la harina de plátano (harina gruesa) no aporta significativamente compuestos o materia que incremente las interacciones de la matriz con el agua o el aceite del medio $y$, por lo tanto, no se da una mayor ni menor capacidad para retener agua o grasa.

Con respecto a la WHC de la harina de plátano, se puede considerar baja comparada con valores reportados en la literatura, por ejemplo: $2,7 \mathrm{~g}$ agua retenida/g de materia seca en salvado de trigo a $42,5 \mathrm{~g}$ agua retenida/g de materia seca en fibra dietética insoluble de zanahoria (Elleuch, et al., 2011); 11,4 a 20,3 en subproductos de espárrago (Fuentes-Alventosa, et al., 2009). Abbas et al. (2011) determinaron la WHC a diferentes temperaturas tanto para cáscara como para pulpa de banano (Musa acuminate $L$., cv cavendshii) con valores que oscilaron de 4,91 a $5,88 \mathrm{~g}$ de agua/g de muestra seca de cáscara y 5,66 a $6,31 \mathrm{~g}$ de agua/g de muestra seca de pulpa. Doporto et al. (2012) determinaron por suspensión de la muestra en agua y centrifugación la WHC de harina y almidones de ñame (Pachyrhizus ahipa (Wedd.) Parodi) y yuca (Manihot esculenta Crantz). Con ambas materias primas la WHC fue mayor en las harinas que en los respectivos almidones. A pesar de que la metodología empleada es diferente a la empleada con la harina de plátano de este estudio, los resultados son similares, dado que para harina de ñame el rango fue entre 1,32-1,91 $\mathrm{g}$ de agua por $\mathrm{g}$ de muestra seca, en el caso de la yuca fue de 1,01-1,10 g de agua por $\mathrm{g}$ de muestra seca. Mweta et al. (2008) reportan también la WHC de almidones de diferentes variedades de yuca con un rango en 0,86-1,08 g de agua por g de almidón seco.

Este comportamiento se ve reflejado en las otras dos propiedades que incluyen interacciones con la harina y el agua, como lo son la solubilidad y el hinchamiento. En la literatura se reporta que la solubilidad para la coliflor varía entre 21,6$48,1 \mathrm{~g}$ solubilizados/g de materia seca (Femenia, et al., 1997), mientras que el hinchamiento varía entre $4,2 \mathrm{~mL}$ residuo/g de materia seca para la coliflor (Femenia, et al., 1997) y 62,2 $\mathrm{mL}$ residuo/g de materia seca para la fibra dietética insoluble de zanahoria (Chau, et al., 2007). 
En promedio, la capacidad de retención de grasa para la harina fue de 0,792 , valor similar al reportado para coliflor, 0,9 g aceite / g de materia seca (Femenia, et al., 1997), e inferior a fibras de desechos de naranja, $195 \mathrm{~g}$ aceite / g de materia seca (Tamayo y Bermúdez, 1998).

\section{Evaluación de las propiedades$$
\text { de la harina en modelos }
$$$$
\text { de emulsiones cárnicas }
$$

Para todos los geles los rendimientos de cocción fueron superiores a 99\%, siendo el valor menor para el gel control. Con respecto a la capacidad de retención de agua del gel, también estuvo por encima de 99,5\% (Gráfico 1).

Según Brewer (2012), al reducir el contenido de grasa se puede aumentar la pérdida de líquidos. Además de lo mencionado anteriormente, Kumar y Sharma (2004) indican que los sustitutos de grasa en su mayoría provocan una reducción del rendimiento y una purga excesiva.

Se determinó que para el rendimiento de cocción existe una diferencia significativa $(\mathrm{p}=0,0006)$ entre tratamientos (Gráfico 1.a). El gel formulado con harina fina al $2 \%$ y el gel control fueron los de menor rendimiento de cocción. Los geles formulados con 2 y $4 \%$ de HF y los de 4 y $6 \%$ de HG no mostraron diferencia significativa. El rendimiento de cocción fue mayor para los geles que contenían algún grado de sustitución, contrario a lo esperado según la literatura, aunque se puede concluir en general que los rendimientos fueron satisfactorios y que este aspecto deberá evaluarse en experimentos más relacionados a la escala industrial.

El aumento en el porcentaje de rendimiento de cocción pudo deberse a que la harina presentaba un alto contenido de almidón, lo que genera un aumento en la capacidad de retención de agua y por tanto interviene en el peso del producto terminado (Tapia, 2005).

Una propiedad funcional de los geles proteicos es su capacidad para adsorción de agua, la cual se ve favorecida en condiciones adecuadas de temperatura y $\mathrm{pH}$ (Brewer, 2012), ya que las proteínas logran formar de una manera más eficiente estructuras de gel que retienen grandes cantidades de agua y otros componentes alimentarios (Kocher y Foegedind, 1993). La determinación de la WHC permite evaluar la capacidad del gel cárnico de adsorber agua y a su vez indica la estabilidad de la emulsión al ser sometida a un esfuerzo mecánico, en este caso a una operación de centrifugación (Choi, et al., 2011; Femenia, et al., 1997).

Se determinaron diferencias $(p<0,0001)$ en la capacidad de adsorción de agua entre los tratamientos, sin importar el grado de sustitución ni el tipo de harina utilizado con respecto al control (Gráfico 1.b). Esto indica que al utilizar la harina de plátano con cáscara como sustituto de grasa se obtiene un incremento en la capacidad de adsorción de agua del gel cárnico, lo cual podría deberse, como se mencionó antes, a que la harina de plátano con cáscara tiene alto contenido de almidón, componente que le brinda una alta capacidad de retención de agua y gelificación al producto (Linden y Lorient, 1996).

En el Gráfico 2.a se observa que el gel 3, el cual corresponde a la adición de $6 \%$ harina gruesa, es significativamente más duro que el gel control y el gel 4 (harina fina, 2\%). A su vez, las demás sustituciones no presentaron diferencias significativas con respecto al control. Además de que el gel 3 presenta un contenido menor de grasa, lo cual influye en su dureza, presenta un contenido mayor de harina y, por lo tanto, de almidón de plátano en su formulación. La dureza, de acuerdo a Rosenthal (2001), se define como la fuerza requerida para comprimir un alimento entre los molares. Una reducción del contenido graso entre 10 a $25 \%$ en productos de carne triturados afecta la dureza (Brewer, 2012), debido a que la grasa promueve la suculencia, sabor, sensación en la boca, cohesión, estabilidad, jugosidad, terneza, saciedad y la emulsión, de forma tal que alimentos con bajo contenido de grasa presentan una dureza mayor (Kaack y Pedersen, 2005).

Según Smith (2001) y Smewing (2001), las características de gelatinización y temperatura de transición vítrea (Tg) afectan la reología y las propiedades mecánicas de los alimentos basados en almidón, debido a que el cambio estructural implica la fusión de biopolímeros de almidón, desnaturalización de proteínas y la formación de complejos entre moléculas como los azúcares y las grasas, lo cual, en este caso, le brinda al producto un leve aumento en la rigidez.

$\mathrm{Al}$ igual que con la dureza, se determinaron diferencias significativas tanto para la gomosidad (Gráfico 2.e) como para la masticabilidad (Gráfico 2.f). El gel 3 presentó un mayor valor de gomosidad y masticabilidad con respecto a los geles $1,4,5$ y control, y 3 no mostró diferencias con respecto a los geles 2 y 6 . En estas características interviene directamente el contenido de grasa del alimento, ya que esta mejora la sensación bucal y facilita la masticación de los alimentos (De Bruijne y Bot, 2001; Greaser y Pearson, 2001). Por esto, de acuerdo a los resultados obtenidos, una mayor cantidad de harina y por ende mayor contenido de almidón influyen significativamente en la capacidad de masticación y desintegración de los geles formulados.

Con respecto al color de los geles cárnicos formulados, las diferencias detectadas coinciden con el estudio de Choi et al. (2011), en el cual al incrementar los niveles de sustitución en geles cárnicos de cerdo cocidos y sin cocer con fibra de salvado de arroz se obtuvieron cambios significativos en los parámetros de color $\mathrm{L}^{\star}, \mathrm{a}^{\star}, \mathrm{b}^{\star}, \mathrm{C}^{\star} \mathrm{y} \mathrm{H}^{\circ}$.

La luminosidad visual $\left(\mathrm{L}^{\star}\right)$ se define como la cantidad de luz que el estímulo parece emitir y va de una escala de 0 (negro) a 100 (blanco) (MacDougall, 2002). En el caso del gel control, este fue diferente con respecto a todos los tratamientos. Se observó que, independientemente del tamaño de partícula, $L^{\star}$ disminuye al aumentar el grado de sustitución (Gráfico 3.a). Esto podría deberse a que al sustituir grasa por agua y harina cambia la distribución de la luz al aumentar la cantidad de agua y de pigmentos provenientes de la harina, lo que puede aumentar la retención de la luz en la estructura de los geles y reflejar menos.

Según Kaack y Pedersen (2005), varios experimentos han demostrado que el bajo contenido de grasa en salchichas provoca productos más oscuros, más rojos y menos amarillos comparados contra las salchichas control. El enrojecimiento $\left(a^{*}\right)$ es la coordenada cromática de rojo $\left(+\mathrm{a}^{*}\right)$ a verde $\left(-\mathrm{a}^{*}\right)$ (MacDougall, 2002). Para los geles analizados, los valores de $\mathrm{a}^{\star}$ se encuentran en el eje positivo, es decir que los geles tienden más al rojo que al verde. Se determinaron diferencias significativas entre el control y los geles 3 ( $6 \%$ de harina gruesa), 5 ( $4 \%$ de harina fina) y 6 ( $6 \%$ de harina fina) (Gráfico 3.b), siendo el control el que presentó menos enrojecimiento. Los geles con mayor grado de sustitución presentaron el mayor enrojecimiento.

El amarillo $\left(b^{*}\right)$ es la coordenada cromática de amarillo $\left(+b^{\star}\right)$ a azul $\left(-b^{\star}\right)$ (MacDougall, 2002) y los resultados obtenidos indican que se tiende a más amarillo que a menos 
amarillo. Se determinaron diferencias significativas entre el control y los demás geles sustituidos, pero no entre los geles sustituidos (Gráfico 3.c). Este comportamiento puede deberse a que en el gel control existe una mayor cantidad de grasa $y$, por lo tanto, una mayor concentración de pigmentos como carotenoides. Estos suelen aumentar la intensidad del amarillo en los productos; al reducirse el contenido de aceite en los demás geles se reduce el amarillo en el color del producto. Así lo afirman Kaack y Pedersen (2005), quienes indican que una reducción en el contenido graso provoca una disminución significativa del amarillo. Estos resultados son contrarios a los citados por Choi et al. (2011), quienes determinaron un aumento significativo en geles de carne de cerdo crudos y cocidos con niveles crecientes de fibra de salvado de arroz, en emulsiones cárnicas sustituidas con fibra de trigo (Choi, et al., 2011) y en tortas de carne para hamburguesas con la adición de película de avellana (Turhan, et al., 2005).

El croma $\left(C^{*}\right)$ representa la distancia vectorial desde el centro del color espacial hasta el color medido (MacDougall, 2002). Según los valores obtenidos, se determinaron diferencias significativas entre el control y los demás geles cárnicos, siendo el gel control el que presenta un croma mayor, mientras que entre los geles sustituidos no se observaron diferencias significativas entre sí (Gráfico 3.d).

Los resultados en cuanto a las diferencias de croma son muy variables. Por un lado, Choi et al. (2011) afirman que las diferencias $\mathrm{C}^{\star}$ de geles crudos y cocidos aumentaron con los niveles crecientes de fibra de salvado de arroz, al igual que al adicionar cáscara de tomate seco a embutidos secos (Calvo, et al., 2008) o al agregar un concentrado de fibra dietética a partir de melocotón en salchichas (Grigelmo-Miguel, et al., 1999). Por otro lado, Mansour y Khalil (1999) no hallaron cambios de color en tortas para hamburguesas con fibra de trigo bajas en grasa, y Dzudie et al. (2002) indicaron que las diferencias de croma no fueron significativas en embutidos de carne sustituidos con harina de frijol. Estos últimos concuerdan más con lo que se determinó para los geles cárnicos sustituidos con harina de plátano con cáscara.

Además de la luminosidad visual y el croma, el ángulo de matiz $\left(h^{\circ}\right)$ es el tercer parámetro más importante en la explicación del comportamiento de los colores en el tiempo y se da como un ángulo entre 0 y $360^{\circ}$ (MacDougall, 2002). Se determinaron diferencias significativas para los geles 3,5 y 6 con respecto al gel control que tenía mayor $\mathrm{h}^{\circ}$ (Gráfico 3.e).

En el caso del plátano, el ángulo de matiz para los geles sustituidos se determinó entre $79,2^{\circ}$ (gel 6) a $85,4^{\circ}$ (gel 1). El control presentó un ángulo de $88,7^{\circ}$. Esta tendencia decreciente del ángulo de matiz se vio más acentuada al utilizar la harina fina, debido a que se dispersa mejor en el gel cárnico gracias a su menor tamaño de partícula, y al aumentar el grado de sustitución se logra disminuir la tonalidad del gel modelo, tendiendo a tonos más amarillos.

\section{Conclusiones}

Con respecto a la composición química de las harinas evaluadas, solo se observaron diferencias significativas en la humedad y carbohidratos. No se observaron diferencias significativas en los dos tipos de harinas estudiados en lo que respecta a su capacidad de absorción de agua (WHC), que en promedio fue de 1,56 g de agua/g harina, la solubilidad (S), cuyo promedio fue de $1,58 \mathrm{~g}$ harina/g agua, el hinchamiento
(SW), en promedio $3,84 \mathrm{~mL} / \mathrm{g}$, y capacidad de absorción de grasa (FAC), que fue de $0,792 \mathrm{~g}$ aceite/g harina.

La harina de plátano verde con cáscara representa una fuente de almidón en la formulación de un producto cárnico y es una opción para sustituir grasa, principalmente por su composición química y características tecnofuncionales.

Bajo las condiciones analizadas en esta investigación, el factor más importante a considerar en el desarrollo de un producto cárnico es el porcentaje de sustitución, el uso de igual o menor a un $4 \%$ de harina fina, que representa un $20 \%$ de disminución de grasa y es el recomendado a fin de disminuir el impacto sobre el color y la textura. Sin embargo, deberá evaluarse el contenido final de carbohidratos para cumplir con la legislación respecto a la composición proximal del producto.

\section{Referencias}

Abbas F.M., Alkarkhi, Saifullah, Bin Ramli, Yeoh, Shin Yong y Azhar, Mat Easa, 2011. Comparing physicochemical properties of banana pulp and peel flours prepared from green and ripe fruits. En: Food Chemistry, 129, pp.312-318.

AOAC International, 1990a. Official methods of analysis of AOAC international. 15a ed. Gaithersburg: AOAC. Official Method 920.85.

AOAC International, 1990b. Official methods of analysis of AOAC international. 15a ed. Gaithersburg: AOAC. Official Method 923.03.

AOAC International, 1990c. Official methods of analysis of AOAC international. 15a ed. Gaithersburg: AOAC. Official Method 925.09.

AOAC International, 2005. Official methods of analysis of AOAC international. 18a ed. Gaithersburg: AOAC. Official Method 920.152.

Bortoluzzi, R., Shimokomaki, M. y Marangoni, C., 2005. Avaliação das características funcionais da fibra de laranja para aplicação em emulsões de carne de frango. En: Congresso Brasileiro de Ciência e Tecnologia de Carnes. Carne es Saúde, 6, pp.1-3.

Brewer, S., 2012. Reducing the fat content in ground beef without sacrificing quality: a review. En: Meat Science, 91, pp.385-395.

Calvo, M., García, M. y Selgas, M., 2008. Dry fermented sausages enriched with lycopene from tomato peel. En: Meat Science, 80(2), pp.167-172.

Chau, C., Wang, Y. y Wen, Y., 2007. Different micronization methods significantly improve the functionality of carrot insoluble fibre. En: Food Chemistry, 100, pp.1402-1408.

Chang, H. y Carpenter, J., 1997.Optimizing quality of frankfurters containing oat bran and added water. En: Journal of Food Science, 62, pp.194-202.

Choi, Y., Choi, J., Han, D., Kim, H., Lee, M., Kim, H., Jeong, J. y Kim, C., 2011. Effects of rice bran fiber on heat-induced gel prepared with pork salt-soluble meat proteins in model system. En: Meat Science, 88, pp.59-66.

Codex Alimentarius, 1989. Directrices generales del Codex para la utilización de productos proteínicos vegetales en los alimentos [En línea]. Roma: Codex. [Consulta: 02 de noviembre del 2011]. Disponible en: http://www. codexalimentarius.net/download/standards/324/CXS_174s. pdf;jsessionid=9EBEDC7270F1A10B58B5C19D8D28C80A

De Bruijne, D. y Bot, A., 2001. Alimentos elaborados basados en grasa. En: Rosenthal, A. J. Textura de los alimentos. Zaragoza: Acribia. 
Doporto, M.C., Dini, C., Mugridge, A., Viña, S. y García, M. A., 2012. Physicochemical, thermal and sorption properties of nutritionally differentiated flours and starches. En: Journal of Food Engineering, 113, pp.569-576.

Dzudie, T., Scher, J. y Hardy, J., 2002. Common bean flour as an extender in beef sausage. En: Journal of Food Engineering, 52(2), pp.143-147.

Elleuch, M., Bedigian, D., Roiseux, O., Besbes, S. y Blecker, C., 2011. Dietary fibre and fibre-rich by-products of food processing: Characterization, technological functionality and commercial applications: A review. En: Food Chemistry, 124, pp.411-421.

FAO, 2011. Examen de la viabilidad técnica del seguimiento $y$ análisis de la importancia económica de variedades de banano distintas de la Cavendish: esbozo de una estrategia [En línea]. Yaoundé: FAO. [Consulta 24 de setiembre de 2012]. Disponible en: www.fao.org/docrep/meeting/022/ ma590s.pdf.

Femenia, A., Lefebvre, A., Theabaudin, J., Robertson, J. y Bourgeois, C., 1997. Physical and sensory properties of model foods supplemented with cauliflower fiber. En: Journal of Food Science, 62(4), pp.635-639.

Fuentes-Alventosa, J., Rodríguez-Gutiérrez, G., JaramilloCarmona, S., Espejo-Calvo, S., Rodríguez-Arcos, R., Fernández-Bolaños, J., Guillén-Bejarano, R. y JiménezAraujo, A., 2009. Effect of extraction method on chemical composition and functional characteristics of high dietary fiber powders obtained from asparagus by-products. En: Food Chemistry, 113, pp.665-671.

González, C., Aristizábal, J. y Aristizábal, M., 2009. Evaluación biológica del manejo de picudos y nematodos fitopatógenos en plátano (Musa AAB). En: Acta Agronómica, Colombia, 58(4), pp.259-269.

González, O. y Pacheco-Delahaye, E., 2006. Propiedades físicas y reológicas de la harina de banana verde (Musa AAA) en la elaboración de geles de piña (Ananas comosus L. Merr.). En: Revista de la Facultad de Agronomía, Maracay, 3, pp.27-40.

Greaser, M. y Pearson, A., 2001. Alimentos de carne y sus análogos. En: Rosenthal, A. J. Textura de los alimentos. Zaragoza: Acribia.

Grigelmo-Miguel, N., Gorinstein, S. y Martín-Belloso, O., 1999. Characterization of peach dietary fiber concentrate as a food ingredient. En: Food Chemistry, 65, pp.175-181.

Hernández, J., Cañizares, A., Blanco, G., Arrieche, I., Pérez, A., Salazar, C. y González, M., 2009. Contenido de nitrógeno, fósforo y potasio en harinas de clones de musáceas comestibles (Musa spp.). En: UDO Agrícola, Venezuela, 9(2), pp.449-457.

Islas, J., Rodríguez, S., Agama, E., Pacheco, G. y Bello, L., 2007. Evaluación de algunas propiedades químicas de un polvo rico en fibra preparado a partir de harina integral de plátano [En línea]. ICA: México. [Consulta abril de 2012]. Disponible en: https://www.google.com.uy/ url? $\mathrm{sa}=\mathrm{t} \& \mathrm{rct}=\mathrm{j} \& \mathrm{q}=\& \mathrm{esrc}=\mathrm{s} \&$ source $=$ web $\& \mathrm{~cd}=1 \& \mathrm{ved}=$ 0CB0QFjAA\&url= http\%3A\%2F\%2Fwww.respyn.uanl. mx\%2Fespeciales\%2F2007\%2Fee-12-2007\%2Fdocumen tos\%2FCNCA-2007-17.pdf\&ei=8OlQVNSmDsKhNuEgJAM\&usg=AFQjCNGpbDVJkeMRA0Uh8Y4vhaZ dRB7QIg\&sig2= Ivt5O81Hsp6pKaHOxO2iaQ\&bvm= bv.78597519,d.eXY\&cad=rjt.

Kaack, K. y Pedersen, L., 2005. Application of by-products from industrial processing of potato flour and yellow peas as ingredients in low-fat high-fiber sausages. En: European Food Research and Technology, 221, pp.313-319.

Kocher, P. y Foegeding, E., 1993. Microcentrifuge-based method for measuring water-holding of protein gels. En: Journal of Food Science, 58(5), pp.1040-1046.

Kumar, M. y Sharma, B., 2004. The storage stability and textural, physico-chemical and sensory quality of low-fat ground pork patties with Carrageenan as fat replacer. En: International Journal of Food Science and Technology, 39, pp.31-42.

Linden, G. y Lorient, D., 1996. Bioquímica agroindustrial. Revalorización alimentaria de la producción agrícola. Zaragoza: Acribia. ISBN: 978-84-200-0805-9.

López-López, I., Bastida, S., Ruiz-Capillas, C., Bravo, L., Larrea, M., Sánchez-Muniz, F., Cofrades, S. y Jiménez-Colmenero, F., 2009. Composition and antioxidant capacity of low-salt meat emulsion model systems containing edible seaweeds. En: Meat Science, 83(3), pp.492-498.

MacDougall, D., 2002. Colour in food. Boston: Woodhead Publishing Limited; CRC Press.

Mansour, E., Khalil, A., 1999. Characteristics of low-fat beef burgers as influenced by various types of wheat fibers. En: Journal of the Science of Food and Agriculture, 79(4), pp.493-498.

Mazzeo, M., León, L., Mejia, L., Enith, L. y Botero, J., 2010. Aprovechamiento industrial de residuos de cosecha y poscosecha del plátano en el departamento de Caldas. En: Educación en Ingeniería, 9, pp.128-139.

Mestres, C., Colonna, P., Alexandre, M.C., Matencio, F., 1993. Comparison of various processes for making maize pasta. En: Journal of Cereal Science, 17, pp.277-290.

Molina, G., 2001. Bananos: alimentos y riqueza [En línea]. Montpellier: INIBAP. [Consulta: 07 de setiembre de 2011]. Disponible en: http://bananas. bioversityinternational.org/.

Murillo, F. y Pacheco, C., 1994. Atlas agropecuario de Costa Rica. San José: UNED.

Mweta, D.E., Labuschagne, M.T., Koen, E., Benesi, I. y Saka, J., 2008. Some properties of starches from cocoyam (Colocasia esculenta) and cassava (Manihot esculenta Crantz.) grown in Malawi. En: African Journal of Food Science, 2, pp.102-111.

Pietrasik, Z., 2003. Binding and textural properties of beef gels processed with $\mathrm{k}$-carrageenan, egg albumin and microbial transglutaminase. En: Meat Science, 63(3), pp.317-324.

Pinero, M., Ferrer, M., Arenas, L., Huerta-Leidenz, N., Parra, K. y Araujo, S., 2008. Atributos sensoriales y químicos de un producto cárnico ligero formulado con fibra soluble de avena. En: Mundo lácteo y cárnico, set./oct., pp.19-23.

Raghavendra, S., Ramachandra, S., Rastogi, N., Raghavarao, K., Kumar, S. y Tharanathan, R., 2006. Grinding characteristics and hydration properties of coconut residue: a source of dietary fiber. En: Journal of Food Engineering, 72, pp.281-286.

Restrepo, D., 2002. Alternativas de industrialización del plátano. Una propuesta [En línea]. Cartagena de Indias: Acorbat. [Consulta 24 de setiembre de 2012]. Disponible en: http://sena.blackboard.com/bbcswebdav/ institution/73311576_1_VIRTUAL/Pdf/Documentos\%20 de\%20apoyo/Doc\%20de\%20apoyo\%204.pdf.

Rosenthal, A., 2001. Relación entre medidas instrumentales y sensoriales de la textura de alimentos. En: Rosenthal, A. J. Textura de los alimentos. Zaragoza: Acribia. 
Sangnark, A., y Noomhorm, A., 2003. Effect of particle sizes on functional properties of dietary fiber prepared from sugarcane bagasse. En: Food Chemistry, 80, pp.221-229.

Sarawong, Ch., Rodríguez-Gutiérrez, Z., Berghofe, E. y Schoenlecher, R., 2014. Effect of green plantain flour addition to gluten-free bread on functional bread properties and resistant starch content. En: International Journal of Food Science and Technology, 49, pp.1825-1833.

SEPSA, 2011. Boletín estadístico agropecuario número 21 [En línea]. San José: SEPSA. [Consulta 24 de setiembre de 2012]. Disponible en: http://www.mag.go.cr/ bibliotecavirtual/a00292.pdf.

Shaibu, A.A., Mji, E.A. y Ogburia, M.N., 2012. Yield evaluation of plantain and banana landraces and hybrids in humid agro ecological zone of Nigeria. En: Journal of Agricultural Research and Development, 2(3), pp.074-079.

Smewing, J., 2001. Hidrocoloides. En: Rosenthal, A. J. Textura de los alimentos. Zaragoza: Acribia.

Smith, A., 2001. Alimentos basados en almidón. En: Rosenthal, A. J. Textura de los alimentos. Zaragoza: Acribia.

Smith, E. y Velázquez, M., 2004. Opciones tecnológicas para la producción del plátano (Musa $A A B$ ) para exportación en la región Atlántica de Costa Rica [En línea]. San José de Costa Rica: MAG. [Consulta: 07 de setiembre de 2011]. Disponible en: http://www.mag.go.cr/bibioteca virtual_ciencia/manual_platano_creditos.pdf.

Soto, V., 2010. Cuantificación de almidón total y de almidón resistente en harina de plátano verde (Musa Cavendishii) y banana verde (Musa paradisiaca). En: Revista Boliviana de Química, 27(2), pp.94-99.

Tamayo, Y. y Bermúdez, A., 1998. Los residuos vegetales de la industria de jugo de naranja como fuente de fibra dietética. En: Lajolo, F. M., Menezes, E.W. ed. Temas en tecnología de alimentos. Vol. 2. México: CYTED.

Tapia, M., 2005. Estructura, clasificación y función fisiológica del almidón resistente. Morelia: Universidad de Michoacana de San Nicolás de Hidalgo. (Tesis de Grado).

Tokusoglu, Ö. y Kemal, M., 2003. Fat replacers in meat products. En: Journal of Nutrition, 2(3), pp.196-203.

Turhan, S., Sagir, I., y Ustun, N., 2005. Utilization of hazelnut pellicle in low-fat beef burgers. En: Meat Science, 71(2), pp.312-316. 